\title{
Six Years of Collaborative Alzheimer's Disease Research in Germany
}

\author{
Christian Haass $^{\mathrm{a}}$ Gerd Multhaup $^{\mathrm{b}}$ \\ aLaboratory for Alzheimer's and Parkinson's Disease Research, Department of Biochemistry, \\ Adolf Butenandt Institute, Ludwig Maximilians University, Munich, and ${ }^{\mathrm{b}}$ Institut für Chemie/Biochemie, \\ Freie Universität Berlin, Berlin, Germany
}

This special issue of Neurodegenerative Diseases is devoted to a 6-year program of the Deutsche Forschungsgemeinschaft (DFG), which supported up to 13 projects on cellular mechanisms of Alzheimer's disease (AD) with 7.5 million euros. Since the maximum funding by the DFG for such initiatives is 6 years, the program came to an end in June 2006. The members of this program have used this occasion to present their projects, their major findings and the collaborative network in the form of summarizing articles.

At the International Conference on Alzheimer's Disease in Amsterdam in 1998, Volker Herzog (University of Bonn) and C. Haass discussed for the first time the idea to initiate a nationwide priority program on $\mathrm{AD}$ research with a special focus on cellular mechanisms leading to amyloid- $\beta(\mathrm{A} \beta)$ peptide production and tau aggregation. We both felt that this was about time, since a collaborative research program on this hot topic did not exist in Germany. For us this was quite surprising, since we were used for many years to run collaborative projects with scientists throughout Europe and the United States. Moreover, we had the strong feeling that by this time Germany's AD researchers were split into two opposing groups, the 'Baptists' and the 'Tauists'. This dogmatic separation of the field prevented coordinated and collaborative research for decades in Germany. Moreover, we also found it surprising that in Germany only a small number of research teams existed. This was even more surprising, knowing that Germany looks back to a fantastic tradition of excellent AD research. Needless to say, that it all started in Germany, when Alois Alzheimer described for the first time the brain pathology of a heavily demented patient exactly 100 years ago (November 1906). Furthermore, Germany is also the place where the $\beta$-amyloid precursor protein ( $\beta$ APP) gene was cloned. This major breakthrough was possible due to the pioneering work of Konrad Beyreuther, who is now regarded as the father of modern $\mathrm{AD}$ research. A number of the members of this network are his 'children' or 'grandchildren'.

The idea behind our initiative was to bring together molecular biologists working in $\mathrm{AD}$ research from complementary fields and opinions and to provide a novel platform for collaborations. In addition, interdisciplinary collaborations should be initiated by including cell biologists. Finally, we wanted to create an opportunity for young investigators to start their own and independent research.

The DFG-sponsored priority program represents an optimal opportunity to support such collaborative nationwide research on novel ideas, which allows all interested scientists throughout the country to work in the field and to benefit from a collaborative network. The program runs for 6 years, with international reviews at the beginning and after every other year.

\section{KARGER}

Fax +4161306 1234

E-Mail karger@karger.ch

www.karger.com (c) 2006 S. Karger AG, Basel

$1660-2854 / 06 / 0035-0193 \$ 23.50 / 0$

Accessible online at:

www.karger.com/ndd
Prof. Dr. C. Haass

Laboratory for Alzheimer's and Parkinson's Disease Research

Department of Biochemistry, Adolf Butenandt Institute

Ludwig Maximilians University, DE-80336 Munich (Germany)

Tel. +4989218075 471, Fax +4989218075 415, E-Mail chaass@med.uni-muenchen.de 


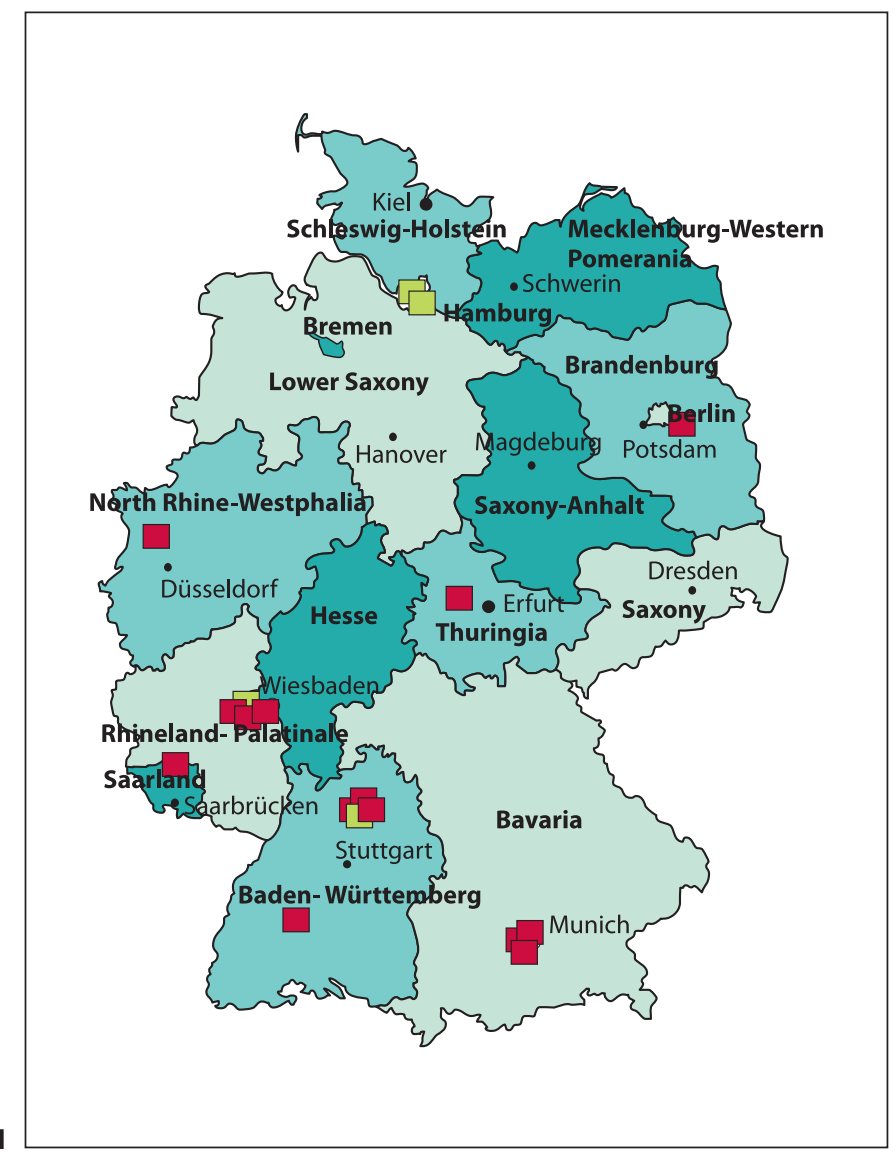

Fig. 1. Alzheimer laboratories of the Priority Program SPP 1085 in Germany (only members of the last funding period are shown). Newly and previously established laboratories are in red and green, respectively.

Fig. 2. The 6th Eibsee Meeting.

Fig. 3. Impressions from the Eibsee V and VI conferences. A Left to right: Eckhard Mandelkow (MPI, Hamburg), Raymond Kelleher (MIT), Rudi Tanzi (MGH and Harvard Medical School), Tobias Hartmann (Center for Molecular Biology Heidelberg), Dora Kovacs (MGH and Harvard Medical School), Jee Shen (Harvard Medical School), and Eva Maria Mandelkow (MPI Hamburg). B Peter St. George-Hyslop (University of Toronto). C Christoph Hock (University of Zürich). D Charles Glabe (University of California, Irvine). E Frank LaFerla (University of California, Irvine). F Michael Shelanski (Columbia University). G Gang Yu (University of Texas). $\mathbf{H}$ Zugspitze, Eibsee, and the lake at sunrise. I Fred van Leuven (University of Leuven). J Peter Kloetzel (Charite, Berlin) and (right) Gerd Multhaup (Free University Berlin). K Peter Breuer announcing the first Award of the Hans and Ilse Breuer Foundation. L Harald Steiner (Ludwig Maximilians University Munich) receiving the Hans and Ilse Breuer Award for Alzheimer's Disease Research. M Dietrich Reinhardt (Dean of the Medical Faculty of the Ludwigs Maximilian University of $\mathrm{Mu}-$ nich) holding the laudatio on Harald Steiner.
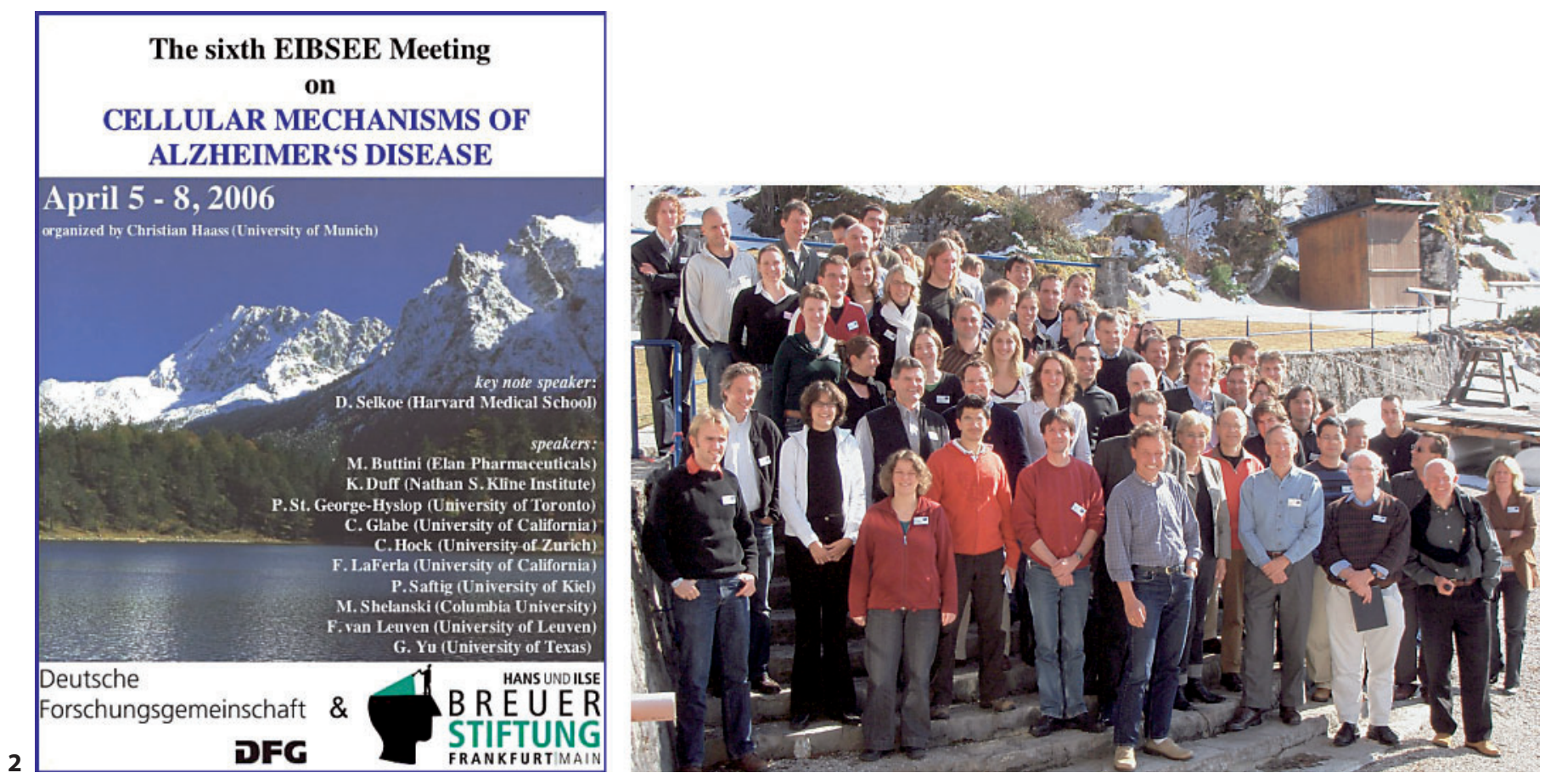

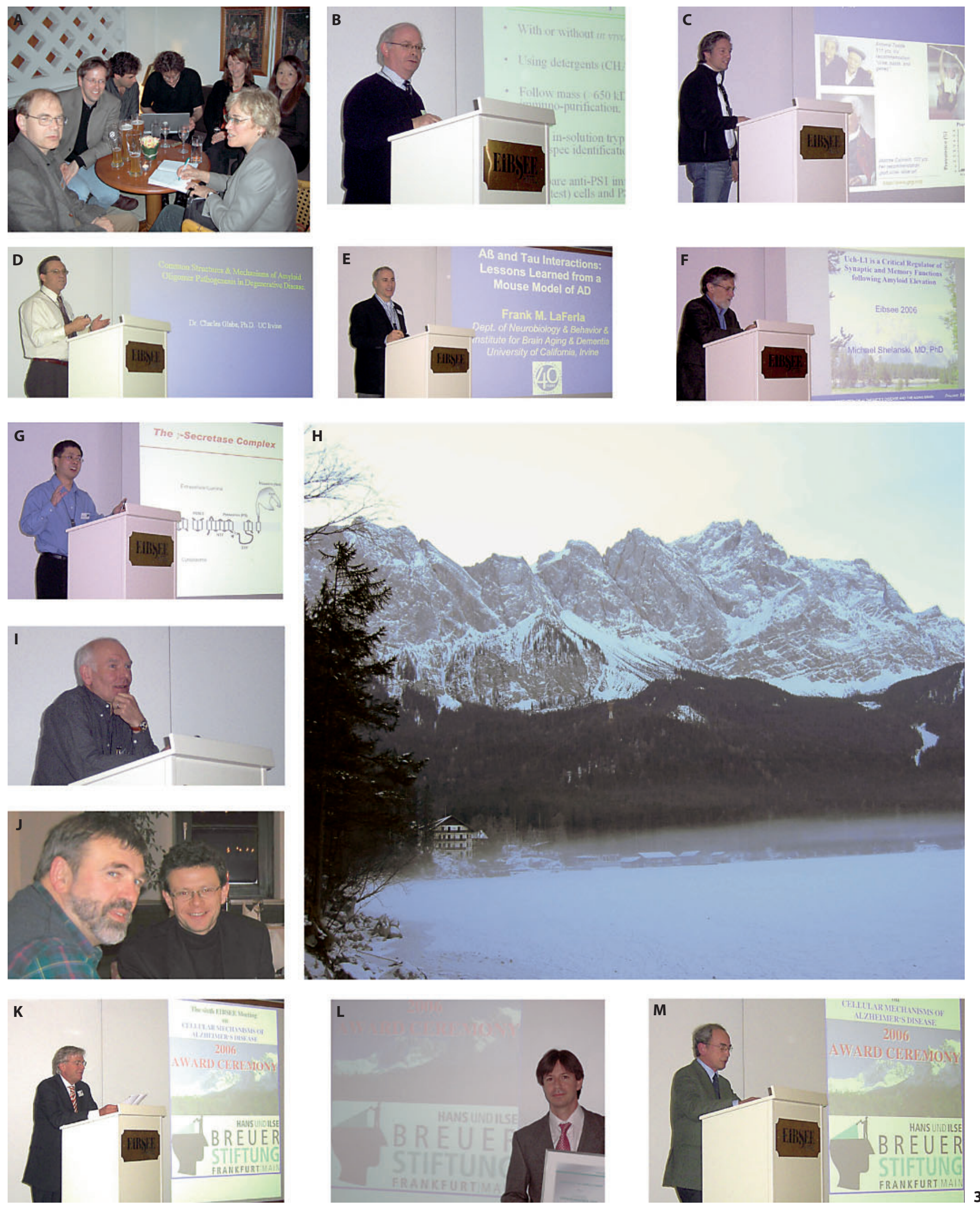
After a first and very successful review, the program started under the name 'Priority Program SPP1085 Cellular Mechanisms of Alzheimer's Disease’ in spring 1999. We covered many aspects of modern AD research centered around the cell biology of APP, the three different secretase activities and tau. These included in vivo analysis of APP transport, functional analysis of presenilin, identification and reconstitution of $\gamma$-secretase, assembly of the $\gamma$-secretase complex, identification of novel $\gamma$ secretase substrates, $\gamma$-secretase function in animal models (Caenorhabditis elegans and Drosophila), cellular analysis of $\gamma$-secretase complex components, life imaging of $\gamma$-secretase trafficking, identification of $\gamma$-secretaselike proteases, functional analysis of APP and its homologues in mice and primary neurons, effects of cholesterol on $A \beta$ peptide generation, functional analysis of $\mathrm{BACE}$ and its dimerization, phosphorylation of secretases, the role of $\alpha$-secretase in the prevention of $A \beta$ production, tau aggregation, and effects of abnormally phosphorylated tau on cellular transport. In addition, projects related to novel therapeutic strategies based on the cellular and molecular mechanisms discovered in our program were initiated. Drugs were screened for their potential to block tau aggregation and its detrimental effects on cellular transport, $\gamma$-secretase modulators were investigated for their potential to selectively inhibit $A \beta$ peptide generation without affecting Notch signaling, and novel compounds were designed to block and investigate secretase activities. The outcome of these projects will be summarized by the members of the SPP1085 in their articles in this special issue of Neurodegenerative Diseases. In addition, a list of publications originating from the SPP1085 projects can be found below. By going through these articles one can immediately appreciate that $\mathrm{AD}$ research in Germany grew together to a group of internationally competitive scientists. Tauists are now even working with Baptists! Moreover, we established a growing number of novel research teams led by young investigators (Drs. Weggen, Kaether, Lichtenthaler, Kins, and Steiner). Furthermore, several members of the SPP1085 obtained major positions at German Universities (Drs. Baumeister, Hartmann, Pietrzik, Schmidt, Multhaup, Walter, Müller, and Haass), and laboratories focusing on $\mathrm{AD}$ are now distributed throughout Germany (fig. 1).
Besides funding the research projects, the DFG also supported annual meetings to allow discussion and exchange of data. All members and their co-workers, the reviewers, and selected speakers from all over the world were invited to these meetings. The meetings took place at a rather remote place in the Bavarian Alps and are now known as the Eibsee Meetings. Six such meetings were held throughout the funding period including satellite meetings of the project leaders in Hamburg and Berlin where the co-speaker of the SPP has accepted the chair for biochemistry during the funding period (G. Multhaup, Free University of Berlin). These conferences turned out to be an excellent platform for generating new collaborations and for bringing together German AD researchers. This meeting developed to an internationally well-recognized conference. Importantly, the very special 'Eibsee atmosphere' allowed detailed informal discussion during hiking and at the fireplace in the evening (fig. 2, 3). Here, many novel ideas and collaborations developed, frequently with inclusion and advice of our international guest speakers and reviewers. The Eibsee Meeting is now the German platform for AD research. We are extremely excited that the Hans and Ilse Breuer Foundation will generously support this meeting in the future. At this year's Eibsee VI conference (the last meeting sponsored by the DFG), the foundation already invited Dr. Dennis Selkoe as a keynote speaker. Moreover, the Hans and Ilse Breuer Foundation will not only help to keep German AD researchers together by supporting the Eibsee conference, but will also directly support $\mathrm{AD}$ research in Germany by offering a major research award (EUR 100,000) and several stipends for $\mathrm{PhD}$ students. It is our great pleasure to congratulate Dr. Harald Steiner as the first recipient of this award.

Finally, we want to thank the DFG (Drs. Golla and Schmidtmann) for the strong support throughout these years. We also greatly acknowledge the tremendous work and important scientific advice from the international board of reviewers (Drs. St. George-Hyslop, Glabe, Heppner, Kloetzel, van Leuven, Saftig, and Aguzzi). Many of them not only had to review numerous applications but also travel long distances for the final board meetings and our conferences.

We are looking forward to fruitful and long-lasting excellent AD research in Germany based on this successful DFG program! 